\title{
REFLECTIONS ON CYBERMIND, V1.0
}

\section{Transforming Cultures eJ ournal, \\ Vol. 2 No 2, December 2007 \\ http:// epress.lib.uts.edu.au/journals/TfC}

\section{Salwa Ghaly ${ }^{1}$}

This short piece attempts to reconstitute and reflect upon my impressions of the world of Cybermind, the cyberlist I joined in the spring of 2001. At the time, I resided in the United Arab Emirates, an important fact to underline at the outset, as my initial reactions and views on cyberspace were undoubtedly coloured by my geographic and cultural situatedness as much as by how my gender and ethnic identity played out online. Although I present, in what follows, a personal account, I would like to posit that my conclusions regarding gender dynamics on Cybermind reflect not only my own experience of/on online lists, but possibly that of other women listers as well. On Cybermind, women listers are caught between, on the one hand, the list as a would-be rhizomatic space holding out the liberatory promise of multiple playing fields for all, women included, and, on the other, the regulatory apparatuses working to align disembodied with embodied space, such that the former comes to refract, if not reflect, the latter. In what follows, I seek to share with the readers some thoughts, often disjointed, on how, despite all our efforts and wishes to make of the internet an empowering space for women, women's voices in cyberspace can be censored, curtailed and excluded through online verbal and nonverbal processes and actions that seek to inscribe hierarchy and order by assigning and maintaining traditional gender roles.

\section{Coming to Cybermind}

To reflect upon my personal trajectory on Cybermind is to try to unpack my first steps into cyberspace, the gingerly steps of a woman who found in Alan Sondheim's cyberlist

\footnotetext{
${ }^{1}$ Salwa Ghaly is a professor teaching English and Humanities at Vanier College in Montreal. After earning her Ph.D. in comparative literature and medieval studies in the late eighties, she decided to abandon her predictable life in Toronto for a taste of the Lebanese civil war, an experience that plunged her headlong into war narratives and other artistic reflections on societies which, despite their great human capital, experience(d) the failure of social contracts. She had the good fortune to witness the postwar reconstruction of Lebanon and the, at times faltering, attempts at reconciliation. Since those years, she has been interested in texts about (or composed in) borderlands and liminal sites/spaces where ethicopolitical choices prod individuals to straddle cultures, religions and languages and to destabilize traditional perspectives on self and other, identity and nationality.
} 
a safe space in which to seek self-affirmation and to experience new possibilities of 'being-online'.

Back in the spring of 2001 when I found Cybermind quite by chance, I was living and working in a secluded corner of the UAE, literally surrounded by the desert. Before discovering the wondrous world of Cybermind and what it had to offer, I had been using the internet solely for research purposes, a need that was accentuated by the dearth of academic resources and tools at my university. The internet provided access to ideas and information that I sorely needed. It was also an instant and effective means of communication with better-placed, better-served colleagues in the West. Though I enjoyed what I did-teaching English literature on a women's campus at a fledgling university in the Gulf-I thirsted for all that was important to me and that was in short supply where I was located on the periphery, namely, connection with the 'core' and a partaking in contestatory discourses and debates. I also yearned for a certain rebelliousness of spirit so lacking in a conservative and conformist society, a rebelliousness that, for me, could only be found in virtual space. In the company of Alan Sondheim, Rose Mulvale and their wonderfully human and fantastically diverse fellow-Cyberminders, I sought to escape the shackles of gender and location. In the disembodied world of the list, I experienced embodied human connectedness and a myriad of human emotions, ones that continue to be important for me today.

Countless memories could have served as entry points into this personal reflection on Cybermind. Despite the fact that, due to time constraints, I have not been on the list for three years, I recall with great vividness some thrilling and enriching exchanges with listers, both male and female. The list was, and continues to be, a magnet for some very accomplished minds who, experimenting with the limits and possibilities of the internet and electronic media, have produced cutting-edge net.art. as well as contributed significantly to the exploration of virtuality, language and meaning. For me, Cybermind, was my marketplace of ideas, the niche where I situated myself in cyberspace, and to which I would resort often on a daily basis seeking multiple perspectives on events and issues. And the listers did not disappoint. From all corners of the globe, frequent posters engaged the physical and the spiritual, mind and matter, politics and society. And they did so in a variety of registers and fashions. At times, the mood of the list would turn exuberantly ludic, and posters would adjust their tone and 
timbre accordingly. The list saw commonplace quotidian realities defamiliarized through the brilliant eyes of Rose Mulvale, who, from her home in Nova Scotia, would invariably transform the most mundane local events into poetic utterances and objects of Socratic contemplation! Her playfulness would elicit mirthful and spirited responses from the fjords of Norway to the velds of South Africa. In wide contrast to my constrained surroundings, Cybermind thus offered not only exhilarating exchanges, but also a multitude of voices and a plurality of perspectives all inhabiting the same space. It was on Cybermind that I had my first and most fulfilling experience of a list. In some other lists I have known, women can feel unwelcome. Where they have been the target of harassment, intimidation and verbal abuse, they often opt out or are reduced to silenced/silent lurkers. Indeed, the online environment is far from being a level playing field for woman; rather, it is often as adversarial an environment as corporate boardrooms. I have had occasion to ponder the mechanisms that silence women in cyberspace, having once been in a situation where I had to quit a list solely because my emphatically-articulated secular views were at variance with the religious convictions of the list moderator. It was then that I realized how special, perhaps even unique in my experience, Cybermind was, being an empowering space in which I could express myself as a woman without expecting opposition simply because of that fact. Even when my opinion was contested, this was generally done in an amicable way, suggesting that the sense of community prevailed over individual differences of opinion, and people who argued did so in a way that did not disrupt the list and alienate members. On this list it thus seemed possible to have strong disagreements and yet remain at ease. In one case where I had disagreements with one fellow lister [we will call him K], K, while sticking to his guns, made every effort to temper his language and tone in a conscious effort to 'humour' me. More often than not, I felt that Cyberminders were trying to 'meet me halfway' so that disagreements would not turn into ugly confrontations. Male listers’ attempts at turning serious arguments presented by women into 'light-hearted jokes' may well betray sexist attitudes; however, such verbal ploys and attempts at humour seem to be equally symptomatic of a desire to keep the community together and to stave off conflict.

For a variety of reasons, Cybermind was (and still is) able to avert traditional list tribulations: unlike many other similar forums, it was open and welcoming; it did not use restrictive gate-keeping to police new members and impose strict protocols. Equally 
important, many of its members were, to use Ricoeur's term, "benevolently spontaneous” in their online rapports with fellow listers. To the key and most prolific members of the list, posting seemed to amount to an act of ethical primacy, a way of reaching out to an 'other' out there in the world; indeed, writing was an act of solicitude towards that other.

Although tensions could sometimes be felt between certain members, those tensions usually remained within what one might consider to be the limits of 'civility' in the 'real world'. Cybermind was neither plagued by trolls nor by intellectual 'pretenders'. I felt that people communicated for the sake of genuine communication. Many had been list members since the inception of the list in the mid-nineties. A few had even met at a Cybermind conference in Australia or elsewhere. In short, Cybermind was, to me, not a list but a community, my community online where I felt most safe and at home.

That is not to suggest that Cybermind was perfect, or some kind of utopia: a cyber community is as vulnerable to political and ideological rifts as any actual community. On Cybermind, I learned about the perils of community building online and how such communities become tenuous if not sustained. I also experienced the intriguing feeling of being viewed as 'the exotic woman' from the Middle East, and could explore the myriad ways in which I was othered even while being solicitously treated.

Being in contact and community also meant being in conflict. Perhaps a definition of community might hinge on the ability to be in conflict without causing fracture. Being in conflict was also frequently marked by issues of gender and assumptions about gender that, in some ways, seemed to put my gendered body and other restrictions back in place. Heated discussions, especially when members of different genders were on different sides, tended to be laden with gender markers.

\section{Gender in Conflict}

To frame same of the issues relating to gender in cyberspace and, specifically, on Cybermind, I would like to register the following observations and reflections: 
1. Men delineate the direction of the general argument, explicate theoretical assumptions, contextualize the discussion within an academic discourse, and extrapolate on theory.

2. Women react to what is argued, often distancing themselves from any academic context/discourse, questioning the value and validity of this context and undermining the value of the 'academic lingo', which, in their eyes, appears to be alienating. The women's point of departure is experiential reality and their experience of cyberspace. They talk from the gut about their cyber 'I's, often complaining about being misunderstood. Some refer to how even when they adopted an intellectual register, they were propositioned for cybersex, etc.

3. The men then propose 'a disinterested, liberal' abstract look at the 'levelling' potential of cyberspace. Revelling in wishful thinking, they argue that gender is insignificant and that the body is absent. What they feel in cyberspace, or think they feel, they are all too ready to extend to women, making their perception of 'maleness online' the lens through which they focalize women's online experiences. These same males will reimport the body very quickly should the prospect of offlist intimacy or contact arise.

4. However, should they attempt to change registers onlist and bring in the body and their own online awareness of their gender, should they make what appears to be a genuine attempt to engage the women on the 'experiential plane', or share their sense of displacement, they are often quickly rebutted and made to feel suspect by the women posters who retort with "What can you know about oppression?" and the like. They are thus summarily tagged as "clueless WASPs", or something similar, and declared inadequate for the task. Effectively then, the men find themselves unable to dwell on personal experience and so are forced back into the kind of theoretical discourse that the women are uncomfortable with in the first place.

5. A vicious circle is created: male use of argumentation puts some women on the defensive; when defensive, they riposte 'aggressively' (in some cases their criticism is unjustified, and they appear to deliberately misinterpret an argument presented by a male poster). The men (and I only refer to the well-intentioned ones here) then do not 
see any use in talking about emotions and experiences, as this register strips them of some of their prestige while incurring the wrath of the women. For that reason, they revert to presenting and rephrasing the same arguments all over again, just to have the last word.

6. As a result, myopia sets in; more men jump in to debate tangential and insubstantial issues, while the women fall silent vindicated that "male list members are incurable sexists.”

7. Certain males who escape being tagged as 'clueless' are perceived as patently sympathetic to the women's vantage point. Responses to them from women posters tend to be more serious and well thought out. Such males are obviously perceived as nonthreatening and might even be perceived as non-sexual.

8. It is more common for males than for females to think it is acceptable, or even virtuous, to be offensive and to use offensive language. What is to be gained by that, other than tending to drive women, or those with greater sensitivity out? Decency, courtesy, genuine interest in a topic further communication. Glib one-liner ripostes often show lack of seriousness or regard for the other, strike a discordant note, truncate discussions and, therefore, hamper communication. This is a moral position perhaps, but one is entitled to ask: Does free speech entitle one to hound others in a flippant and smug manner whenever disagreements arise? Does such freedom of speech not end free speech for others? After all, online, words can be weapons. And the non-gender neutral language that is often wielded online can be used to exclude and marginalize women in cyber forums.

9. Upon a fresh re-reading of several discussions or arguments about gender and gender roles, on the whole I am troubled by the defensiveness of the women and by the fact that few among them are willing to engage new angles on gender issues. I wonder why that is so. Is this due to the disproportionately high number of academic or academically-inclined men in this cyber community? Had these debates been going on in an academic list where respondents have more or less the same educational background and interests, would the results/posts/tone have been different? Looking at some of the transcripts of posts from 2001-2004, I feel that the potential was there for 
both women and men to really take the discussion to a higher, more constructive plane, but that did not happen. Was this simply because the men were eager to appropriate an academic discourse that women resisted, a discourse that they hoped would put them on a 'higher', more privileged, intellectual plane? I suspect that the very logocentric language plied by the men in their 'rational/logical/enlightenment register' was quickly picked up by the women posters as metonymic of male power. This language replicated the oppressive structures that these debates were all about in the first place.

It seems then that the language in which men's arguments are couched was a serious impediment to the fostering of good will and a genuine desire to let one's guard down. At times, I felt anger, frustration but most of all suspicion in the women posters later complemented by anger and frustration from the other side, leading to a vicious circle within which no constructive debate could be conducted.

The implication of the above points is that, in some crucial ways, language styles and usage are incredibly powerful in creating effects that may not be intended and that may be intensified by the cyber medium, because words are all we have online. I now want to briefly explore this thought further by looking at the ways that language can produce both a sense of intense connectedness and, conversely, a sense of danger, which may or may not be present in ways that we normally consider to be present in our offline life.

\section{Back-channelling Online}

The internet seems in some ways charged with sexuality, possibly due to the fact that the virtual medium ignites and inflames people's curiosity on more than one plane, including the sexual. It seems that online space has the capacity to open people up to one another. While I have not experienced this phenomenon myself, my back-channel correspondence with several Cyberminders leads me to believe that this aspect of cyber culture is alive and well on the list. Since net romance has been thoroughly investigated by other list members, I will limit myself below to some general observations.

In cyberspace, even a mundane correspondence between people who may or may not know each other can gain an extra sparkle and take on a new dimension. A clever comment in one email message followed by an equally clever riposte, or repartee, can breathe romance into an otherwise humdrum cyber correspondence or even office 
relationship. One cannot, therefore, underestimate the power of the cyber medium and its ability to render imaginations hyperactive. Gender is never absent in cross-gender cyber communication, and there is always a chance that a sustained online correspondence might turn into overt flirtatiousness then romance.

What is most intriguing is how words in such situations acquire inordinate weight, words being all that correspondents possess online: the ways one person addresses another in a post, the ways s/he ends a message, the questions, the tone, the punctuation, all play an important role in distancing a person and keeping them at arm's length or, conversely, bringing them closer. Thus, even in the absence of an overt and intentional exchange of intimacies and personal information, paratextual devices and emoticons, pregnant with non-verbalized meanings, can become vehicles by means of which emotions and sensations are communicated and shared. Choice of diction, diacritical marks, and literary devices to preamble or end messages, play a role in registering emotional responses and states. Words are made flesh in cyberspace in ways that people may well experience viscerally. Words can shrink distance between people or amplify it multi-fold.

It seems that the power of the mind and the power of imagination (and one's psychological needs, too) play a monumental role in breathing life into words and making for what can be very intense emotional responses and sensations. Words sustain correspondents' emotional investment; through words, they feel the weight of the unsaid, of the silence. One cannot, therefore, underestimate the presence of the body in all of this cyber traffic of information and people.

Just as email lists and back-channelling between list members can bring people together, igniting all sorts and levels of interest, the opposite can happen when a list member is harassed, hounded, intimidated or stalked. In a few instances while on Cybermind, and on other lists as well, I felt that certain male members became overbearing and overly intrusive. On two occasions, when faced with unwelcome messages, I appealed to the authority of long-time listers as well as to moderators whom I trusted and respected. In both cases, I had ample support from my online 'friends' from whom I sought help and advice. The Cybermind 'community' restored my 
equanimity and helped me retrieve my 'feeling of wellness online'. And it is to this 'community' that I now turn.

\section{Community}

In my experience, it is largely the moderator who makes or breaks a list. A supportive moderator can help maligned or flamed list members weather many a flame war. This support can manifest itself in many ways and gestures, and may take some offlist form. When I, as list member, feel that I am dealing with a fair moderator who endeavours to keep the list open and pluralistic, I am more inclined to give that list a second and third chance.

At one point around 2002, I had occasion to join another list, which, like Cybermind, appeared to concern itself with topics related to cyberculture. When I first joined, I was startled by the degree of self-disclosure in which male list members were involved. Initially, I assumed that recurrent instances of male introspection, soul searching and self-revelation would correlate favourably with male openness to discussions revolving around gender issues. The strong list presence of several vocal left wingers also reinforced my early positive impressions, at a time when a few Cyberminders espousing right-wing views following September 11, adversely impacted an otherwise-progressive list. Reading the two lists concomitantly was, thus, a fascinating experience, and one that gave me a fresh perspective on gender dynamics online. Compared to the right wingers on Cybermind, the male voices on that other list were much more open-minded. I, therefore, assumed that they would be amenable to engaging women's thoughts on and perceptions of gender issues. Those early impressions quickly proved to be erroneous: whether this was due to gender, ethnicity, views on religion or my situatedness in the Gulf shortly after 9/11, I cannot tell for certain. I simply felt I was assailed by several list members at once, and by the moderator of that list more than all the others combined. The concerted and, in my opinion, unwarranted attack from members rattled me far less than the attitude of the list owner who seemed to me at the time to be actively trying to chase me off his list. That is exactly what transpired.

Most list owners I have known are intrusive and straitjacketing. One of Alan Sondheim's strengths, I have always believed, is precisely his unobtrusiveness, graciousness, tolerance and deep commitment to free speech, qualities that in my view, 
unlike that of Jon Marshall, are an expression of power, rather than powerlessness. That type of moderation that Alan elected for his list decidedly gives Cybermind its special character. Having a supportive moderator may be more important for women on lists where they are a minority. Subsequently, Alan's retreat from moderation, splitting it between several others, may well have changed Cybermind and contributed to a sense of alienation that I felt on the eve of the war on Iraq, as I discuss later.

Others have suggested that Cybermind's success lies in the Cyberminders' sense of community and commitment to felicitous communication. And for much of my experience of that list, I was able to express myself freely without having to contend with censorious voices. Indeed, there was a time when only on Cybermind could I say whatever I felt like saying confident that this would not jeopardize my status or voice on the list. This said, much of what gives a list its character takes place behind the scenes, something that a list researcher is likely to bracket out of her purview, precisely because that form of one-on-one communication is mostly inaccessible to her. What made Cybermind welcoming and supportive was the list life beyond the list itself. Backchannel correspondence, which naturally never appeared before others, was used to reduce or resolve conflict, reassure harassed list members as well as encourage posters to continue posting, thereby keeping the list alive and interesting.

Women colleagues/associates/friends certainly use this back-channelling all the time and we talk about ourselves a lot more than I suspect men do among themselves. So many indications point to the fact that back-channelling is going on all the time. One long-time member, with an intimate knowledge of the list and its oral memory, reported to me that 'the boys' talk about Formula 1, sports, jokes and cyber-relations among Cybermind members past and present, but he would not elaborate. I suspect that they also discuss new members and perhaps even condition reactions to them. It may also be the case that cross-gender communication is even more marked.

In this context, I cannot help but remember Rose Mulvale and the tremendous support she lent new list members. Maintaining much more visibility than most women or men, she performed, without doubt, a pivotal role and made other women feel welcome. People who perform her function have an indispensable and positive role to play, as she would encourage women listers to post and become more visible. In my early days on 
Cybermind, she sought to reassure me and to make sure I continued to post, and she did so both onlist as well as back-channel. At times, she would say the kind of thing that men might have wanted to hear; I particularly remember a thread on "vicious women”, in which she was uncharacteristically non-feminist. In another instance, she tried to defend my "uppitiness" by suggesting that a stifling Arab culture had made me so, as if my perceived militancy were some kind of ailment that one had to justify or explain away. However, these are minor points when compared with her extraordinarily positive influence on the list for as long as she was on it.

It would be useful to trace Rose's trajectory onlist and to discover how she established her status on Cybermind. What were her perceived strengths? How did she change over the years? To what extent did her 'real life' encounters with some list members enhance or change her position onlist? But, without recourse to Cybermind's early archives, that task would be impossible.

Rose was a person of great human dignity, and was frequently described by list members as "the heart of the list". Perhaps this was a role she could play because of stereotypical perceptions of women as 'nurturing'. But it was a remarkably well-played role, and although others seemed to try to take her place when she was away, no one quite succeeded. Her death in 2002 was a cause of great distress amongst us. I recall thinking at the time how much of a privilege it had been for me to have known Rose albeit briefly and virtually. I likewise recall marvelling at how strong a virtual bond forged in cyberspace could be and how that bond had most of the attributes of a face-toface relationship.

This provokes the question of how the list has changed following Rose's passage. In many ways, it was no longer the same list for me. Rose catalyzed Cybermind in womenfriendly ways, promoting every once in a while some 'women-only' threads to which a cluster of women listers would contribute. Much of that was subsequently lost.

As well as by people, community can be triggered by external events. Thus, I noticed that the September 11 crisis brought several lurkers out of 'lurkdom', but all too briefly, suggesting that, though these people are listeners and not active participants, they felt part of the CM community and could, when they needed to, 'jump in'. To the extent that 
this is the case, they may not be as marginalized as some might think. I corresponded offlist with one of them and found that, despite his lack of participation, being comembers of Cybermind gave us a strong sense of a shared list experience.

I recall thinking that the 'intimidation' of which some lurkers spoke was less a function of the spirit of the list or its modus operandi than a feeling that was occasioned by those lurkers' own need to break the ice and invest some time contributing posts. The sooner a new member posts the better, because, in my experience, once a lurker always a lurker, at least on a given list. This may be truer of women than of men.

On reading the posts of those who 'de-lurk', one quickly realizes that they are as articulate as the best posters on any list. Additionally, they bring refreshing new angles on issues that a list will recycle from time to time. Their silence is definitely the list's loss, all the more so since most of those who delurked appeared to be women, and we needed more women posters on Cybermind. No matter how hospitable the list was there was always the discrepancy in numbers. Men dominated, whether they would or not, because of sheer numbers.

I was tempted to tell the lurkers that a few posts to test the waters (or cyber waves) would probably demonstrate that Cybermind was no 'frat club', had no initiation rites (that I knew of, anyway) and no obsessive gate-keeping policies. However, as mentioned earlier, even when listers did not participate, they still seemed to feel that they belonged to the list.

However, communities change, and so did Cybermind. Cybermind's community faced its greatest challenge on the eve of the Iraq War and during the immediate months thereafter. Politics and boundaries became imported into a space that was supposedly isolated from 'real life'. I found the reaction difficult. Some forwarded articles carrying grim news; there were intense arguments focusing usually on whether or not those nonAmericans opposing the Bush Administration's policies were anti-American. Some Americans asked if non-Americans were simply anti-American in principle, as if there were no grounds, for some, to oppose Bush's policies. A few posters retreated or unsubscribed unable to handle the stress of many frayed nerves and much bickering onlist. When the bleak mood of the war gave way to light-hearted one-liner messages, 
possibly intended to be less 'political' and therefore more inclusive, I found myself turned off by the 'flippant' tone used by some American listers, especially given the scale of destruction in Iraq and the human toll of that war. I started deleting whole threads unread. I faulted Alan, in a way, because way back when I mentioned to him that the alliance between two list members in particular was alienating others and driving some off the list, he defended one of the two posters stating that the list needed more people like that person. Yet that person's posts painfully highlighted in the starkest of terms the chasm separating me and my perspective on Iraq from that of mainstream America at the time. Those posts rendered the list inhospitable and made me recoil. With the other serious participants receding into the background, there did not seem to be much left of the list.

My alienation was compounded by my sense that I was alienating others online and losing friends who were dear to me on account of my political views. On Cybermind, I felt isolated and unwelcome, although others who disagreed with me complained that they too were feeling that way. The war in Iraq and comments on it onlist outraged me and made me feel impotent, depressed and voiceless. For the first time since joining that list, Cybermind provided no escape from reality, and no place in which to discuss what I felt or what was happening. For me, that period more or less marked the end of Cybermind as I had experienced it prior to the Iraq war.

\section{Communication Problems: Ecriture feminine?}

I would like to wrap up this piece with a few more abstract considerations about language, communication and gender.

If we agree on a certain set of norms, speech markers, discursive practices, and attribute them to men and women, we put women in a difficult bind: if they use ratiocinative methods of argumentation, they can be considered to have 'sold out' and bought into a male language, accepting a position that can only be subordinate in this discourse. If they use "le parlé femme" or the pre-linguistic "le semiotique" or women’s "babble"whatever those 'discourses' translate into in actual, not theoretical, terms-they also opt for an exclusionary kind of discourse that may or may not promote communication. To what extent can I, a woman, rely on chora (which is not distinctly gendered according to Kristeva), to make me intelligible in a revolutionary language all my own and distinct 
from male-dominated modes of communication hitherto employed? If so, where are the prototypes and the models? This is the gruelling question that is not altogether different from the literary one that eventually drove the likes of Virgina Woolf to the brink of despair. How can we create a female tradition ex nihilo where no 'original' models exist? How can we rely on a tradition that is all-male and saturated with anti-feminist sentiments and values without unwittingly imbuing our own work with those values?

Although I very much believe that we speak the way we are taught to speak and argue (and that speech, argumentation and silence are learned and are often gendered), I fear that working with/within such heuristic language markers may lead us to place more tags and limitations on women. I fear essentialism. If I use argumentation and ratiocination, I would not wish to be accused of adopting an 'inauthentic' or a 'male' voice. (In post-structuralist terms, that very notion has become extremely suspect, as we know.) Is irony the only mode open to us, the tool of the underdog? Or should we continue our deconstructive tactics hoping to dent this monumental phallocratic order? But even Derrida uses logic and argumentation to defeat logic and argumentation. Some of the means we use to empower ourselves will be perceived and tagged as 'male' ones. Should we rename those means and appropriate them arguing against what has been considered groundbreaking work on gender markers in cyberspace? Should we come up with a contending list of markers, less strait-jacketing for women academics who, as things now stand, feel self-conscious about the language they use on a daily basis to put bread on the table and actualize themselves in their respective professions? I say this realizing full well that 'academic' language wielded by women often earns her onlist resentment.

In some ways this is a problem faced by writers in other places. Previously I explored how in borderlands identities which enunciate positions of fixity are called into question, but perhaps only if people choose to make that questioning. We could propose that borderlands are frontier sites where the crossing of mental and/or physical borders is highly desirable and ethical, if not always possible. They are sites in which the hitherto absolute Other can be integrated together in the self thereby redefining the parameters of identity and rendering dichotomizing, essentializing binaries, such as gender and racial categories, suspect. Yet as we have seen, these sites are also ones in which people promulgate hierarchy and the old system. 
These borderlands are places in which absence or exclusion can become presence, in which presence becomes ambiguous, where the other has the potential to lose her invisibility, and people can try to engage one another across the borders of race, religion, gender or ethnicity. In these physical or imagined spaces, polarized groups can work conjointly toward disabling stereotypes that kill. Or, of course, people can attempt to enforce the dichotomies, and kill the messengers telling us these are not essential.

In a nutshell, I have come to the conclusion that one adopts procrustean moulds at one's own peril; for no theory will ever fit either gender like a glove. 